This document is the accepted manuscript version of the following article:

Möhring, N., Ingold, K., Kudsk, P., Martin-Laurent, F., Niggli, U., Siegrist, M., ...

Finger, R. (2020). Pathways for advancing pesticide policies. Nature Food, $1,535-540$. https://doi .org/10.1038/s43016-020-00141-4

\title{
Pathways for advancing pesticide policies
}

\section{Niklas Möhring ${ }^{1 *}$, Karin Ingold ${ }^{2,3}$, Per Kudsk $^{4}$, Fabrice Martin-Laurent $^{5}$, Urs Niggli ${ }^{6}$, Michael} Siegrist $^{7}$, Bruno Studer ${ }^{8}$, Achim Walter ${ }^{9}$, Robert Finger ${ }^{{ }^{*}}$

${ }^{1}$ Agricultural Economics and Policy Group, ETH Zurich, Zurich, Switzerland

${ }^{2}$ Institute of Political Science and Oeschger Center for Climate Change Research, University Bern, Bern, Switzerland

${ }^{3}$ Environmental Social Science Department, Eawag, Dübendorf, Switzerland.

${ }^{4}$ Department of Agroecology, Aarhus University, Slagelse, Denmark

${ }^{5}$ AgroSup Dijon, INRAE, Univ. Bourgogne, Univ. Bourgogne Franche Comté, Agroécologie, Dijon, France

${ }^{6}$ Agroscope, Bern, Switzerland

${ }^{7}$ Consumer Behavior, Institute for Environmental Decisions, ETH Zurich, Zurich, Switzerland

${ }^{8}$ Molecular Plant Breeding, Institute of Agricultural Sciences, ETH Zurich, Zurich, Switzerland

${ }^{9}$ Crop Science Group, Institute of Agricultural Sciences, ETH Zurich, Zurich, Switzerland

*Corresponding authors: Robert Finger (rofinger@ethz.ch) and Niklas Möhring (nmoehring@ethz.ch) 
Pest management in agricultural cropping systems is critical for food security ${ }^{1}$ but the adverse effects of pesticides on human health and the environment have been repeatedly shown ${ }^{2-4}$. The reduction of potential risks from pesticide use is widely discussed amongst agricultural policy and food value chain actors worldwide ${ }^{5-7}$. Reduction measures range from the development of new technologies and agricultural inputs to the implementation of more sustainable farming systems and the introduction of food labels. All these strategies are guided, monitored, and supported by public policies (Fig. 1).

\section{Public Agencies and Actors}

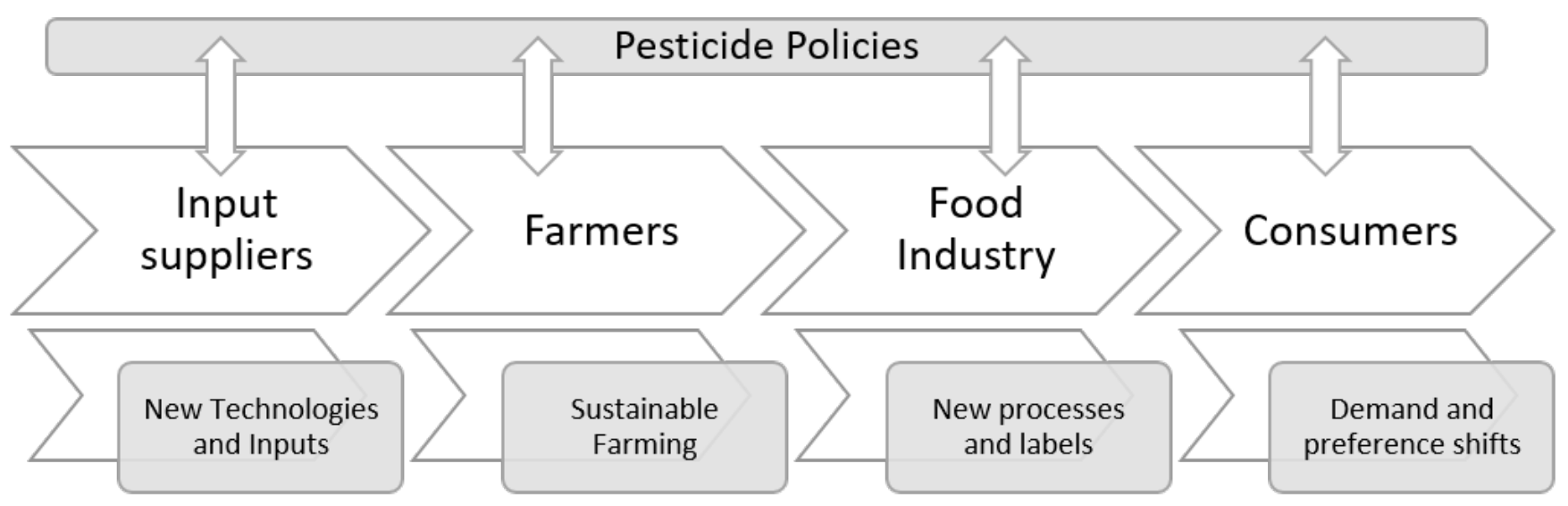

\section{Figure 1. Interactions between food value chain actors and pesticide policies.}

Pesticide policies interact with input suppliers, farmers, the food industry and consumers - each actor can contribute towards sustainable food systems with actions specific to their role (bottom row). Current policy measures can be classified as command and control measures (e.g. pesticide authorization, bans, use regulations), market-based measures (e.g. pesticide taxes, financial support of new technologies, direct payments) and information-based measures (e.g. education, labelling, awareness raising) (detailed in Figure 2, pesticide policy mix box). Many specific, national or regional measures are contained in each of the three categories and may target conflicting policy goals ${ }^{8}$. 


\section{Mixed success from policy efforts in Europe}

Though risks from agricultural pesticide use are heterogeneous across global regions, Europe serves as a valuable case study for an assessment of policy design and instruments. It has a leading role in implementing pesticide policies and exports standards to interlinked global agriculture, sometimes also referred to as non-tariff trade barriers ${ }^{9}$ - such examples include food quality and safety standards, like maximum residue limits for pesticides on food, or the technical standard of Hazard Analysis and Critical Control Points ${ }^{10,11}$. Direct payments to farmers constitutes a substantial part of farm incomes in Europe and is tied to cross compliance regulations and the provision of multiple ecosystem services.

European pesticide policies include regulatory frameworks, direct payments and, since 2011, mandatory National Action Plans to reduce risks and impacts of pesticide use on human health and the environment (Directive 2009/128/EC). Current assessment of pesticide active ingredients is based on hazards rather than the actual risk exposure of humans and the environment to substances, which would require data collection and monitoring beyond current levels, as well as modelling of impacts on the scale of the whole agricultural system ${ }^{12,13}$.

\section{Despite substantial efforts in the last decade, there is little evidence that Europe has achieved the} reduction in pesticide risks and impacts as mandated in National Action Plans. A direct assessment of policy targets proves difficult, as most European countries do not publish or monitor data on risks - or environmental and health impacts of utilized pesticides on a national level - which is a major weakness of current policies ${ }^{14}$. However, we know that since the introduction of National Action Plans pesticide sales in Europe have remained stable ${ }^{15}$, farmers' usage has not decreased (as seen in France) ${ }^{16}$ and surface and groundwater contamination still regularly exceed legal thresholds ${ }^{4,17}$. This suggests weak effects of current policies - in line with general public perception in Europe that current agricultural policy does not sufficiently consider the protection of the environment ${ }^{18,19}$. Pesticide policies need to be revised and advanced. Here, we take a multi-disciplinary view and outline current research that show ten pathways to a successful reduction of potential risks from agricultural pesticide use.

\section{Policy indicators, targets and design}

Tangible pesticide risk indicators. Specific and measurable targets are required to achieve a reduction of potential environmental and health risks from agricultural pesticide use ${ }^{20}$. Risks and indicators to measure those risks - require definition, which are missing in most European countries ${ }^{21}$. Purely quantitative indicators (i.e. kilograms of active ingredients or number of standard dosages) are currently used for a posteriori risk assessment, but quantitative measures alone do not necessarily correspond with potential environmental and health risks. Policies 
focusing on quantity reductions could induce the use of low-dose pesticides with a higher efficacy on target organisms but at the same time a stronger (eco)-toxicological effect on nontarget organisms ${ }^{22}$. Effective and efficient policies require national governments to prioritize country-specific reduction goals for potential environmental and health risks, set tangible indicators to quantify the specified potential risks and transparently monitor and publish data on these risks at a national level. New sensor and monitoring technologies increasingly allow the implementation of cheaper, real-time monitoring systems of risks over time and space ${ }^{23,24}$. Denmark demonstrates that spatially explicit and risk oriented indicators can help to establish successful policies, which achieve a reduction in pesticide $\operatorname{load}^{25}$.

Dimensions of policy targets. Policies typically focus on intensive margins, i.e. potential risks of specific crops or products, such as the ban of neonicotinoids ${ }^{26}$. However, pesticide use is highly heterogeneous across crops and different agricultural systems ${ }^{16,27}$. Policy-induced changes in farmers' land use through extensive margins, such as the switch from one crop to another, or super-extensive changes, like switching from conventional to organic farming, have large effects on use levels. Extensive and super-extensive margin effects may even point in the opposite direction of intensive margin effects. For example, a subsidized insurance may induce reductions in use levels per hectare, but lead to an expansion of economically more risky crops that are often more pesticide intensive ${ }^{28}$. Therefore, it is crucial for policies to consider intensive, extensive and super-extensive margins in the design and evaluation of policy measures (Fig. 2), allowing for long-term implications of policies regarding land and technology use. Critical discussions are required about targets for pesticide use levels and more sustainable land use and agricultural systems at a regional and landscape level ${ }^{29,30}$.

Realignment of agricultural policy goals. European agricultural policies aim to enable multiple ecosystem services and to be aligned with UN Sustainable Development Goals ${ }^{29,31}$, but stricter pesticide policies could have unintended side-effects on other policy goals, and vice versa ${ }^{19}$. For example, they might induce changes in land use and management practices that could decrease food production and quality, increase soil erosion or lead to higher greenhouse-gas emissions ${ }^{27}$. Banning specific pesticides might even foster the use of more harmful ones ${ }^{32}$. Resistance management is key in this regard: banning currently registered compounds, while only slowly marketing new, lower-risk active ingredients, makes alternation of active ingredients impossible in the long-run. Unintended side-effects of policy measures need to be clearly acknowledged and quantified by all actors; policy measures that reduce trade-offs have to be prioritized. Marketbased policy instruments, such as taxes, are particularly suited to incorporate external costs and trade-offs into decisions made by farmers, the food industry and consumers. Long-term vision and commitments of policies are needed to foster investments and the development of efficient strategies. Moreover, to gain momentum, strong and persistent policy signals to the actors of the food value chain are needed. A good example is the successful establishment of a large-scale 

cereal production program with highly reduced pesticide use over the last 30 years in Switzerland, which is based on an interplay of governmental direct payments, a market-based price mark-up and labeling to consumers ${ }^{27}$.

\section{Farmer and consumer actions}

Farmer decision-making processes. Although all actors of the food chain are involved in the reduction of potential pesticide risks, crucial pest management decisions are made at farm level 33. Pest development and weather conditions are processes with major stochasticity, leading to uncertainties in crop growth and efficiency of pesticides ${ }^{34}$. Risk perception and preferences of farmers - and information about uncertainties - influence their evaluation of pest management costs and gains so that they may not follow a strictly profit maximizing rationale ${ }^{35}$. Further, behavioral factors, such as perception biases and habits influence the farmers' decisionmaking ${ }^{36,37}$. Effective policies must consider farmers' heterogeneous behavior and decision rationales ${ }^{38}$ regarding pesticide applications and offer differentiated policy solutions; insurances reducing uncertainty for very risk-averse farmers ${ }^{28,39}$, pesticide taxes or incentives driving shifts in economic behavior ${ }^{40}$, or more information and extension services targeting farmers who lack information on alternatives may work best in achieving policy $\operatorname{targets}^{39}$, respectively. Importantly, farmers' self-selection allows policy-makers to reduce complexity and specificity of well-designed polices - and may increase cost-efficiency. For example, imposing a tax will ensure that those with the lowest marginal abatement costs reduce risks, while those with higher abatement costs, such as producers of high-value crops, do not.

Consumer choices and preferences. Consumers commonly rely on simplistic assumptions when evaluating the risks of chemicals ${ }^{41}$ - the natural-is-better ${ }^{42}$ and contagion heuristics, where laypeople ignore the quantity and focus on the act of contamination ${ }^{43}$, may be especially important in the context of pesticides. Public chemophobia persists and citizens are generally concerned with pesticide use ${ }^{41}$, yet present a strong insensitivity to dose-response relationships 44 . Demand for foods produced with reduced amounts of pesticides may be limited because such labeling would remind consumers of undesirable chemicals used in their foods' production consumers commonly value labels of organic crops produced without synthetic pesticides higher than labels of reduced use ${ }^{45}$. In contrast, free-from labels appear to create biased perceptions because consumers can wrongly conclude that goods without such a label may be less healthy, which is not necessarily the case ${ }^{46}$. Price signals (e.g. incorporating external costs of pesticides) in combination with information have the potential to drive consumer behavior and policies that alter agricultural practices and systems. However, these systems must still produce food products that fulfill consumers' preferences. 


\section{Sustainable plant protection}

Pesticide admissions and regulations. Despite admission of new pesticides to the European market being strongly regulated and following the precautionary principle, new evidence on adverse effects are found and dozens of formerly registered pesticides are now restricted or banned ${ }^{47}$. Simultaneously, fewer new active ingredients are authorized ${ }^{48}$. Admission reassessments focus on individual active substances and are governed by their current authorization expiration date, rather than adopting a holistic, long-term strategy. For residue levels, retailers creating stricter private standards does not necessarily lead to safer products but might increase the risk of gaps in plant protection measures and pest resistances.

Development and registration of new and safe pesticides requires improvements to the admission process. In the pre-authorization phase, creation of a single authority for handling active ingredient authorization and monitoring would improve coordination and unify the authorization process. Instead of relying on industry-supplied data, more assessments by anonymous, accredited laboratories would increase credibility and trustworthiness whilst reducing conflicts of interest. Environmental parameters should be used to assess potential risks from transformation products. Registrations limited to safer, more efficient products would enable faster postauthorization risk assessment, whilst shorter time periods between market release and risk investigation by public bodies would improve the authorization process ${ }^{49}$.

Currently, risk assessments only focus on single pesticides and single crops - a more holistic view of risk assessments on the landscape level is needed to assess real world pesticide use ${ }^{12}$. Agreed definitions of low-risk products in fast-track authorization systems with lower data requirements and long-term authorization periods are required to enable farmers to replace banned, toxic pesticides with products containing less harmful active ingredients, whilst simultaneously maintaining effective resistance management. A dynamic policy framework would support pesticide vigilance in all European countries ${ }^{50}$ - such programs have already been established in Denmark (see https://www.forskningsdatabasen.dk/en/catalog/2389310167) and are being implemented in France ${ }^{51}$.

Sustainable farming systems. Sustainable agricultural systems can potentially decrease agricultural pesticide use ${ }^{30,52,53}$ following the efficiency-substitution-redesign framework ${ }^{30}$ optimizing (e.g. precision farming), substituting (e.g. biocontrol agents or mechanical weed control) and redesigning (in) the current cropping system (e.g. favoring biotic interactions). In Europe, cross-compliance regulations comprise aspects of integrated pest management, with farmers receiving direct payments for conversion to extensive or organic production systems. Despite their potential ${ }^{54}$, tools like prevention and non-chemical pest management are not widely 
considered by farmers due to the knowledge-intensive nature of these systems, the higher risks and potential differences in efficiency, which can result in higher short-term costs than conventional practices ${ }^{3}$. Economic incentives encouraging farmers' adoption of agro-ecological and integrated pest management measures have to account for the farmers' decision rationales and require the support of official and independent advisory services. Current plans for the common agricultural policy (CAP) reform are only addressing these issues indirectly ${ }^{29}$, missing a golden opportunity to promote pesticide-free farming systems.

Plant breeding strategies. For centuries, resistance breeding has contributed to crop productivity and plant disease management ${ }^{55}$, and will continue to be a basic requirement for mitigating potential pesticide risks in Europe. However, plant breeding is a long and complex process, which is often unable to keep pace with the rapid evolution of pathogens or the emergence of new pests - processes that are increasingly driven by globalization and climate change ${ }^{56,57}$. Genomics and new plant breeding techniques provide enormous potential to increase the speed and technical opportunities in the development of resistant cultivars ${ }^{58}$. Current examples include the deployment of resistance sources from wild crop relatives that were lost during domestication ${ }^{59}$ and the specific modification of resistance genes to increase their effect spectrum or to make them more durable ${ }^{60}$. However, the link between the value of advanced plant breeding and the reduction of pesticide use is often neglected in public discussions across Europe.

Regulators face challenges in balancing the benefits of new breeding technologies with potential risks, costs and lack of political support ${ }^{61}$. In the case of genetically modified crops - which have been widely utilized around the globe - strong regulations in Europe, such as restrictions on the co-existence of genetically modified and conventional crops, have hindered wide-spread adoption ${ }^{62,63}$. Despite benefits in pesticide reduction ${ }^{64}$, negative consumer perception of genetically modified crops and knowledge gaps on plant breeding techniques in wider society have maintained a regulatory framework that prohibits the use of the latest gene technology developments. Europe can benefit from technologies like CRISPR/Cas to achieve durable resistance efficiently or provide easy access to resistance sources and crop diversity in gene banks (EU Council Decision L293/103) - these tools can strengthen plant breeding and take advantage of the enormous potential genetic diversity for crop improvement ${ }^{65}$. Thus, European policies require a revision of gene technology regulation in a differentiated, scientifically justified ${ }^{66}$ and practically implementable manner ${ }^{67}$.

Smart Farming. Information and communication technologies will disrupt agricultural practices to potentially reduce agriculture's ecological footprint ${ }^{68}$. Artificial intelligence, for example, can aid detection and classification of weeds, pests and diseases precisely and efficiently; images 
taken from unmanned aerial vehicles or from tractor-mounted spraying booms allow targeted spraying, decreasing applied pesticide quantities. Challenges still remain: occlusion by other leaves or reflective leaf properties can hinder detection ${ }^{69}$ and current or future precision farming technologies are currently mainly profitable for larger farms, e.g. due to economies of scale ${ }^{70}$. Nevertheless, large-scale, rapid adoption will likely occur once these technologies have proven their value in the field, especially through push and pull mechanisms like combining agrienvironmental policy instruments such as taxes and subsidies ${ }^{40,70}$. Finally, investments in technical infrastructure, such as access to high-speed internet connections, satellite images, data platforms - and the development of suitable legal frameworks - are essential for enabling widespread adoption of these technologies.

Efficient and dynamic pesticide policy portfolio. Based on policy from water use and climate change mitigation, the most effective and politically feasible way to reduce potential risks consists of creating a policy mix of source-directed and end-of-pipe solutions ${ }^{71,72}$. Sourcedirected measures, such as taxes on pesticides and carbon emissions or energy, require considerable behavioral change from the target group and are often hindered by political opposition ${ }^{61}$. End of pipe measures, such as filtering or treatment of wastewater, reduces pollution exposure through technical solutions, which are effective but costly. Effective portfolios require so-called creative destruction, where contradictory policy instruments are replaced with new ones and are based on the nature of problems rather than political power games $^{73}$. Thus, policy instruments should account for the complex nature of risk reduction and connect different sectors, decisional levels, and jurisdictional areas (Fig. 2) (4 $^{2}$ an example could be reinvesting revenues from pesticide taxes (incentivizing changes in individual, applicationspecific behaviour) in the promotion of sustainable farming systems, leading to sector-wide support to switch to alternative crop protection techniques ${ }^{40}$. Policies must dynamically adjust to future challenges in pest management, such as changes in pest pressure (e.g. through climate change and invasive species) ${ }^{57,75}$, trade-offs in new agricultural systems or increasing evidence on residues and pollution ${ }^{24}$. This requires the definition of potential policy pathways in response to key challenges - and a monitoring system that can trigger policy actions ${ }^{76}$.

\section{A holistic approach to pesticide policies}

One decade of major pesticide policy efforts have demonstrated that current polices are not effective in reaching their risk reduction goals. Here, we have shown that pesticide policy is bigger than the admission and regulation of single pesticides. Using a holistic framework (Fig. 
2), we outline pathways for a successful reduction of potential risks from agricultural pesticide use without putting other ecosystems services of agriculture at risk.

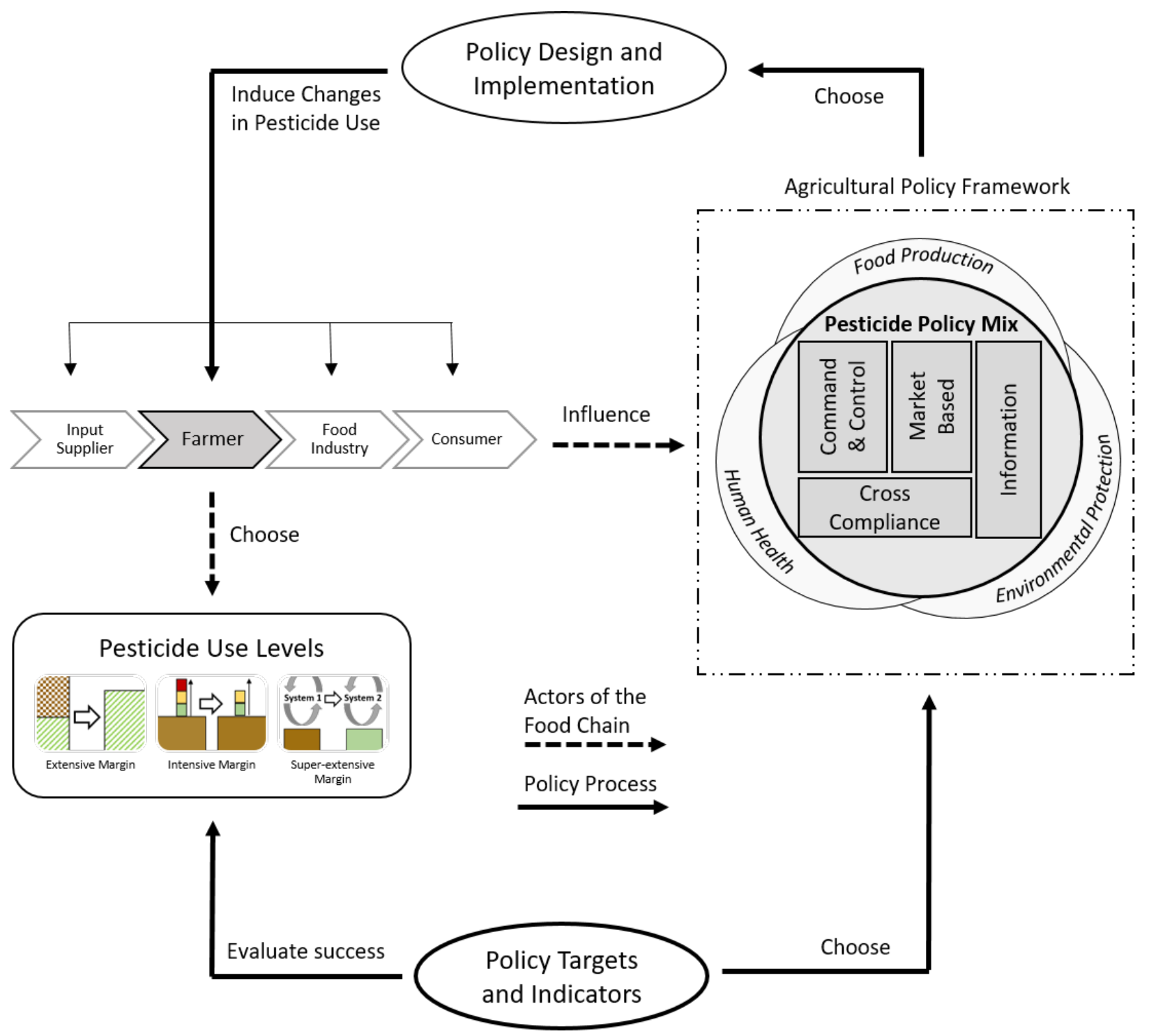

Figure 2. A holistic approach to pesticide policies.

Policy targets and indicators (bottom) feed into the choice of the pesticide policy mix (right), which has to account for interactions between food production, human health and environmental protection - and is embedded in the agricultural policy framework. Design and implementation of policies are essential for their effects on actors (top) and ultimately for farmers' choice of pesticide use levels (left). Success of policies may be evaluated along extensive, intensive and super-extensive margins, which refer to changes in pesticide use levels induced by farmers' land use changes, changes in pesticide use intensity (e.g. per crop or hectare) and changes in the agricultural system (e.g. switch from conventional to organic agriculture), using the defined policy indicators and targets. 
Pesticide policies involve trade-offs and stress-points. Different actors within the food value chain may not perceive all reduction measures as equally promising. New technologies can reduce trade-offs in policies but may not be accepted by consumers. Farmers may not use more sustainable farming practices, new technologies or low-risk compounds if they are less profitable, more complicated and/or less effective than conventional approaches. Further, individual policy goals may contradict each other and lack reliable long-term planning horizons. Bans of single pesticides and diverging private standards for residues may, for example, increase long-term gaps in plant protection and lead to more resistances with severe agronomic consequences.

A new holistic and simple policy framework is needed to improve current pesticide policies. Creating simple, generic and long-term policy goals for all actors in the food value chain reduces policy complexity and maintains flexibility in policy tools and measures. The framework must be based on clear and tangible policy goals that include transparent assessment and monitoring procedures for risks - thus, enabling a transition from the current hazard-based system to a riskbased system. To overcome conflicting goals between food production, environmental protection, biodiversity and human health - and avoid single, isolated solutions for every policy goal and actor in the food value chain - pesticide policy should be integrated in a holistic food policy framework ${ }^{77}$. The political process must be dynamic and policies have to be continuously adapted to fit future changes in agricultural systems. The "From Farm to Fork" strategy, which is at the heart of the EU Green Deal, and the upcoming agricultural policy reforms in Europe present an important opportunity to advance current policies - and to take a major step forward towards the reduction of potential risks from pesticide use. 


\section{References}

1 Savary, S. et al. The global burden of pathogens and pests on major food crops. Nature Ecology \& Evolution 3, 430-439, doi:10.1038/s41559-018-0793-y (2019).

2 Larsen, A. E., Gaines, S. D. \& Deschênes, O. Agricultural pesticide use and adverse birth outcomes in the San Joaquin Valley of California. Nature Communications 8, doi:10.1038/s41467-017-00349-2 (2017).

3 Niggli, U. et al. Wissenschaftlicher Beirat des Nationalen Aktionsplans Pflanzenschutz beim BMEL, 2019: Pflanzenschutz und Biodiversität in Agrarökosystemen., (Wissenschaftlicher Beirats des Nationalen Aktionsplans Pflanzenschutz beim Bundesministerium für Ernährung und Landwirtschaft, Bonn, Germany, 2019).

4 Stehle, S. \& Schulz, R. Agricultural insecticides threaten surface waters at the global scale. Proceedings of the National Academy of Sciences 112, 5750-5755, doi:10.1073/pnas.1500232112 (2015).

5 Lai, W. Pesticide use and health outcomes: Evidence from agricultural water pollution in China. Journal of Environmental Economics and Management 86, 93-120, doi:10.1016/j.jeem.2017.05.006 (2017).

6 Lefebvre, M., Langrell, S. R. H. \& Gomez-y-Paloma, S. Incentives and policies for integrated pest management in Europe: a review. Agronomy for Sustainable Development 35, 27-45, doi:10.1007/s13593014-0237-2 (2014).

7 Osteen, C. D. \& Fernandez-Cornejo, J. Economic and policy issues of U.S. agricultural pesticide use trends. Pest Management Science 69, 1001-1025, doi:10.1002/ps.3529 (2013).

8 Lee, R., den Uyl, R. \& Runhaar, H. Assessment of policy instruments for pesticide use reduction in Europe; Learning from a systematic literature review. Crop Protection 126, 104929, doi:10.1016/j.cropro.2019.104929 (2019).

9 Swinnen, J. Economics and politics of food standards, trade, and development\#. Agricultural Economics 47, 7-19 (2016).

10 Nimenya, N., Ndimira, P. F. \& de Frahan, B. H. Tariff equivalents of nontariff measures: the case of European horticultural and fish imports from African countries. Agricultural Economics 43, 635-653 (2012).

11 Handford, C. E., Elliott, C. T. \& Campbell, K. A review of the global pesticide legislation and the scale of challenge in reaching the global harmonization of food safety standards. Integrated environmental assessment and management 11, 525-536 (2015).

12 Topping, C., Aldrich, A. \& Berny, P. Overhaul environmental risk assessment for pesticides. Science 367, 360-363 (2020).

13 Kudsk, P. \& Mathiassen, S. K. Pesticide regulation in the European Union and the glyphosate controversy. Weed Science 68, 214-222 (2020).

14 European Court of Auditors. Special Report 05/2020: Sustainable use of plant protection products: limited progress in measuring and reducing risks. (Luxembourg, 2020).

15 European Environmental Agency. (European Environmental Agency,, Copenhagen, Denmark, 2019).

16 Hossard, L., Guichard, L., Pelosi, C. \& Makowski, D. Lack of evidence for a decrease in synthetic pesticide use on the main arable crops in France. Science of The Total Environment 575, 152-161, doi:10.1016/j.scitotenv.2016.10.008 (2017).

17 Spycher, S. et al. Pesticide Risks in Small Streams-How to Get as Close as Possible to the Stress Imposed on Aquatic Organisms. Environmental Science \& Technology 52, 4526-4535, doi:10.1021/acs.est.8b00077 (2018).

18 European Commission. Special Eurobarometer 440: Europeans, Agriculture and the CAP. (European Commission Brussels, Belgium, 2016).

19 Huber, R. \& Finger, R. Popular initiatives increasingly stimulate agricultural policy in Switzerland. EuroChoices 18, 38-39, doi:10.1111/1746-692x.12209 (2019).

20 Maxwell, S. L. et al. Being smart about SMART environmental targets. Science 347, 1075-1076, doi:10.1126/science.aaa1451 (2015).

21 European Union DG Health and Food Safety. Overview Report - Sustainable Use of Pesticides. (Publications Office of the European Union Luxemburg, Luxemburg, 2017).

22 Möhring, N., Gaba, S. \& Finger, R. Quantity based indicators fail to identify extreme pesticide risks. Science of The Total Environment 646, 503-523, doi:10.1016/j.scitotenv.2018.07.287 (2019).

23 Saini, R. K., Bagri, L. P. \& Bajpai, A. K. in New Pesticides and Soil Sensors 519-559 (Elsevier, 2017).

24 Rösch, A., Beck, B., Hollender, J. \& Singer, H. Picogram per liter quantification of pyrethroid and organophosphate insecticides in surface waters: a result of large enrichment with liquid-liquid extraction 
51 Ministère de l'agriculture, d. 1. a. e. d. 1. f. in Décret no 2016-1595 (ed LA RÉPUBLIQUE FRANÇAIS) (JOURNAL OFFICIEL DE LA RÉPUBLIQUE FRANÇAIS, Paris, France, 2016).

52 Muller, A. et al. Strategies for feeding the world more sustainably with organic agriculture. Nature communications 8, 1290 (2017).

53 Tschumi, M., Albrecht, M., Entling, M. H. \& Jacot, K. High effectiveness of tailored flower strips in reducing pests and crop plant damage. Proceedings of the Royal Society B: Biological Sciences 282, 20151369 (2015).

54 Lechenet, M., Dessaint, F., Py, G., Makowski, D. \& Munier-Jolain, N. Reducing pesticide use while preserving crop productivity and profitability on arable farms. Nature Plants 3, 17008 (2017). Hickey, L. T. et al. Breeding crops to feed 10 billion. Nature Biotechnology 37, 744-754, doi:10.1038/s41587-019-0152-9 (2019).

56 Chakraborty, S. \& Newton, A. C. Climate change, plant diseases and food security: an overview. Plant Pathology 60, 2-14, doi:10.1111/j.1365-3059.2010.02411.x (2011).

57 Deutsch, C. A. et al. Increase in crop losses to insect pests in a warming climate. Science 361, 916-919, doi:10.1126/science.aat3466 (2018).

58 Chen, K., Wang, Y., Zhang, R., Zhang, H. \& Gao, C. CRISPR/Cas Genome Editing and Precision Plant Breeding in Agriculture. Annual Review of Plant Biology 70, 667-697, doi:10.1146/annurev-arplant050718-100049 (2019).

59 Zsögön, A. et al. De novo domestication of wild tomato using genome editing. Nature Biotechnology 36, 1211-1216, doi:10.1038/nbt.4272 (2018).

60 Oliva, R. et al. Broad-spectrum resistance to bacterial blight in rice using genome editing. Nature Biotechnology 37, 1344-1350, doi:10.1038/s41587-019-0267-z (2019).

61 Metz, F. \& Ingold, K. Politics of the precautionary principle: assessing actors' preferences in water protection policy. Policy Sciences 50, 721-743, doi:10.1007/s11077-017-9295-z (2017).

62 Ramessar, K., Capell, T., Twyman, R. M. \& Christou, P. Going to ridiculous lengths-European coexistence regulations for GM crops. Nature biotechnology 28, 133-136 (2010).

63 Qaim, M. The economics of genetically modified crops. Annual Review of Resource Economics 1, 665-694, doi:https://doi.org/10.1146/annurev.resource.050708.144203 (2009). Smyth, S. J. The human health benefits from GM crops. Plant Biotechnology Journal, doi:10.1111/pbi.13261 (2019).

65 Mascher, M. et al. Genebank genomics bridges the gap between the conservation of crop diversity and plant breeding. Nature Genetics 51, 1076-1081, doi:10.1038/s41588-019-0443-6 (2019).

66 Nationale Akademie der Wissenschaften Leopoldina, Deutsche Forschungsgemeinschaft \& Union der deutschen Akademien der Wissenschaften. Towards a scientifically justified, differentiated regulation of genome edited plants in the EU., (Halle (Saale), Germany, 2019).

67 Ledford, H. CRISPR conundrum: Strict European court ruling leaves food-testing labs without a plan. Nature 572, 15-15, doi:10.1038/d41586-019-02162-x (2019).

68 Walter, A., Finger, R., Huber, R. \& Buchmann, N. Opinion: Smart farming is key to developing sustainable agriculture. Proceedings of the National Academy of Sciences 114, 6148-6150, doi:10.1073/pnas.1707462114 (2017).

69 Mahlein, A. K., Kuska, M. T., Behmann, J., Polder, G. \& Walter, A. Hyperspectral Sensors and Imaging Technologies in Phytopathology: State of the Art. Annual Review of Phytopathology 56, 535-558, doi:10.1146/annurev-phyto-080417-050100 (2018).

70 Finger, R., Swinton, S. M., El Benni, N. \& Walter, A. Precision Farming at the Nexus of Agricultural Production and the Environment. Annual Review of Resource Economics 11, 313-335, doi:10.1146/annurev-resource-100518-093929 (2019).

71 Metz, F. \& Ingold, K. Sustainable Wastewater Management: Is it Possible to Regulate Micropollution in the Future by Learning from the Past? A Policy Analysis. Sustainability 6, 1992-2012, doi:10.3390/su6041992 (2014).

72 Schaffrin, A., Sewerin, S. \& Seubert, S. Toward a Comparative Measure of Climate Policy Output. Policy Studies Journal 43, 257-282, doi:10.1111/psj.12095 (2015).

73 Peters, B. G. \& Hoornbeek, J. A. in Designing Government: From Instruments to Governance (eds Pearl Eliadis, Margaret M. Hill, \& Michael Howlett) 77-105 (McGill-Queen's University Press, 2005). Ingold, K., Driessen, P. P. J., Runhaar, H. A. C. \& Widmer, A. On the necessity of connectivity: linking key characteristics of environmental problems with governance modes. Journal of Environmental Planning and Management 62, 1821-1844, doi:10.1080/09640568.2018.1486700 (2018). 
75 Early, R. et al. Global threats from invasive alien species in the twenty-first century and national response capacities. Nature Communications 7, doi:10.1038/ncomms 12485 (2016). for crafting robust decisions for a deeply uncertain world. Global Environmental Change 23, 485-498, doi:10.1016/j.gloenvcha.2012.12.006 (2013).

77 De Schutter, O., Jacobs, N. \& Clément, C. A 'Common Food Policy’ for Europe: How governance reforms can spark a shift to healthy diets and sustainable food systems. Food Policy, 101849 (2020).

\section{Acknowledgements}

We thank the research team of the Sinergia project "CRSII5_193762 Evidence-based Transformation of Pesticide Governance", funded by the Swiss National Science Foundation, for conceptual support and intellectual inspiration. FML was supported by the ANR project Decisive 'Tracking degradation of soil pollutants with multi-elemental compound-specific isotope analysis’ (Grant number: ANR-18-CE04-0004-02).

\section{Author contributions}

NM and RF conceived of and led the manuscript writing and editing. The manuscript is based on the written input from all authors, which was the basis of the final manuscript. All authors carefully revised the manuscript and approved the submission. 